\title{
UBUNTU IN A POST-APARTHEID SOUTH AFRICAN CONTEXT
}

\author{
By Cornelia van Graan*
}

\section{Introduction}

In this article, I attempt to determine the position and value of ubuntu in the law of post-apartheid South Africa as well as to determine how ubuntu compares to humanitarianism. To achieve this goal, I examine both ubuntu and humanitarianism but I go further than merely an examination of the two concepts in isolation; a determination of the similarities and differences also takes place. The terms to be used in this study will be 'traditional ubuntu', which refers to ubuntu as known and understood by the indigenous people of South Africa, and humanitarianism, as known in the Western civilization.

Ubuntu has a strong traditional meaning and forms part of the indigenous law. Prior to 1994, it played no role in South African jurisprudence. During the transition period from apartheid to a nonracial constitutional democracy, South Africa saw many changes and under this new democratic and constitutional dispensation, the law had to change and adapt to provide for and protect people of all cultures in South Africa. In an effort to extend the law to all people, irrespective of race and culture, the newly-established Constitutional Court moved to include ubuntu into South African law and jurisprudence as a legal value. ${ }^{1}$

Now the questions which need to be addressed are: what exactly is ubuntu? How does ubuntu differ from humanitarianism? What is the effect of the distinction between ubuntu and humanitarianism on the use of ubuntu in South African law? To answer these questions I examine an array of materials including the interim Constitution, ${ }^{2}$ the 1996 Constitution, ${ }^{3}$ case law and writings on ubuntu by the most prominent writers on the subject.

* LLB (UP); LLM (Research) candidate in Criminal Law, University of Pretoria; Admitted Advocate of the High Court of South Africa.

See S v Makwanyane 19956 SA 391 (CC) and PE Municipality v Various Occupiers

20051 SA 217 (CC) where the court interprets and discusses ubuntu.

2 The interim Constitution of the Republic of South Africa, Act 200 of 1993 ('The interim Constitution').

3 The Constitution of the Republic of South Africa, 1996 ('The Constitution'). 
Before I commence the discussion on ubuntu and its application in the South African context, I will attempt to define ubuntu, with reference to the traditional meaning, after which I will define humanitarianism. ${ }^{4}$ This is done to provide the reader with a clear understanding of the aforementioned concepts.

\section{Ubuntu: Traditional or Cultural definition}

Traditionally ubuntu has been defined as 'umuntu ngumuntu ngabantu, motho ke motho ka batho ba bangwe, 5 which in English translates to 'I am a human being through other human beings' 6 In essence, this means that an individual exists because of the community and not in spite of it. Thus the community forms just as much a part of the individual as the individual forms part of it. ubuntu, in its most basic form, is a philosophy of life and law which holds the individual and the community responsible for the well-being of both the community and the individual. Central to this philosophy of life and law is personhood, humanity, morality and dignity. ${ }^{7}$ It is an approach to jurisprudence and philosophy which is opposed to individual actions which are harmful to the community as a whole. ${ }^{8}$ The needs of the whole community are held to be more important than the needs of the individual. ${ }^{9}$

When the definition of ubuntu is examined, certain questions arise: what is the impact of this approach to life and law on the individual? What about the rights of the individual? Does the individual lose his existence and his rights? Can an individual be simultaneously independent and dependent? Does this approach lead to the individual suffering when the community suffers even though he might have the resources not to suffer? What is the implication for the existence of the individual? Does the individual lose his identity to obtain a communal identity? These are difficult questions to answer but I believe that they can be answered with reference to the definition of ubuntu, and a proper understanding and application of ubuntu.

Before I attempt to answer these questions, I will first discuss humanitarianism as an alternative to the traditional understanding of ubuntu.

$4 \quad$ With this I mean a definition that has developed and is developing in line with the Constitution and the new South African legal position also referred to as the western definition or humanitarianism.

5 Y Mokgoro 'Ubuntu and the law in South Africa' in D Cornell \& N Muvangua (eds) Law in the ubuntu of South Africa (2011) 363. Future page references refer to the draft manuscript on file with the author.

6 Mokgoro (n 5 above) 363.

7 NL Maho “O se re homorwa “morwatowe!” African jurisprudence exhumed' (2010) CILSA XLIII 326.a

Mokgoro (n 5 above) 364-365.

$9 \quad$ Mahao (n 7 above) 325. 


\section{Humanitarianism ${ }^{10}$}

What can be seen as the 'Western' version of ubuntu amounts to an approach to life and law often referred to as humanitarianism. Humanitarianism is defined as actions and procedures undertaken while treating people with dignity, respect and equality irrespective of their social status or status in a country. Humanitarianism includes any actions and procedures that place the well-being of humans as its first priority. Humanitarianism is a "concern with the condition of a man considered solely as a human being regardless of his value as a military, political, professional or other unit'. ${ }^{11}$ This approach is fitting for a Western society as it is based on equality, dignity and respect but still aims to keep the individual central to the concept. The protection of individual rights is central to the concept of humanitarianism, but is held in such a manner that it is not harmful to the group or community as a whole. The concept entails that individual rights are important but may be limited to ensure the promotion of the 'greater good'.

\section{Comparison between ubuntu and humanitarianism}

When comparing the two concepts, it is clear that in certain respects they do resemble each other, as both of these concepts in essence frown upon individual actions which have a negative effect on the community as a whole. Further, both concepts are based on the principles of equality dignity and freedom ${ }^{12}$ and encourage actions which advance the community and requires of an individual to develop his or her potential in such a way that there is harmony between the individual and the community.

However, it is clear that even though there are strong resemblances between ubuntu and humanitarianism, they can never

'Humanisme' (humanism) is defined in the Nasionale Afrikaanse woordeboek (National Afrikaans Dictionary) (6th edition) as: 'enige beskouing wat die menslike welsyn vooropstel. Dit is ' $n$ mensliewende beweging' ('any view that places the well-being of humans as its first priority. It is a human-centred movement') (own translation).

11 K Mackintosh 'The principles of humanitarian action in International humanitarian law' (Study 4 in: The politics of principle: the principles of humanitarian action in practice) (2000) (HPG Report 5 March 2000) as contained on http:// www.odi.org.uk/resources/docs/305.pdf (accessed 29 September 2012). CBN Gade 'Historical development of the written discourses on ubuntu' (2011) 3 SA Journal of Philosophy 303-304.

12 Gade (n 11 above) 303-304; T Bekker 'Re-emergence of ubuntu: a critical analysis' in D Cornell \& N Muvangua (n 5 above) 490-491.

13 Mahao (n 7 above) 327. 
be equated ${ }^{14}$ as these concepts differ fundamentally from each other in the sense that, although humanitarianism requires humane actions towards each other, as a Western concept it is still firmly grounded on the importance of the individual, whereas the concept of ubuntu is rooted in community and the wellbeing of the community and deals with 'human centeredness'. ${ }^{15}$

Further, a concern with the potential of the individual, the potential of human beings ${ }^{16}$ and thus the potential of the community forms an integral part of ubuntu, whereas humanitarianism does not deal with the concept of the potential of people - an element which bears great importance within the concept of ubuntu. ${ }^{17}$ Furthermore, humanitarianism only requires equal, just and humane treatment of people and therefore does not deal directly with the community or the needs of the community. Even though humanitarianism and ubuntu are based on some of the same values, they are not one and the same as humanitarianism holds the individual at its centre and ubuntu holds the community at its centre.

After examining both the resemblances and the differences between ubuntu and humanitarianism, it is clear that the concept of ubuntu is the more fitting concept for a post-apartheid South African jurisprudence as it fits into the communal way of living still present and dominant in South Africa.

\section{Ubuntu: existence and rights of the individual}

I will briefly revisit the questions raised above concerning the individual when applying ubuntu. What happens to the identity of the individual? Should the individual suffer because the rest of the community suffers even though he might own the resources not to suffer? Does the individual still have his or her own individual rights or are individual rights sacrificed for the good of the community? What about the individual's freedom of choice to live as he or she pleases?

After a proper examination of ubuntu and a comparison thereof with humanitarianism, it is clear that some of the answers to these questions do seem fair. What happens to the individual's identity? The individual retains his identity but his identity is shaped with reference to the community he forms part of, in other words identity is developed through a set of collective ideals. ${ }^{18}$ The same applies to individual morality. The individual remains individual and maintains

14 Y Mokgoro \& S Woolman 'Where dignity ends and ubuntu begins: An amplification of, as well as identification of a tension in, Drucilla Cornell's thoughts' (2010) SAPL 400.

15 Mahao (n 7 above) 319

Mokgoro (n 5 above) 364-365.

As above.

Mokgoro (n 5 above) 364-365. 
the ability to perform his own tasks and live for himself; but his morality is formed through collective ideals and this causes him to act in a manner which is not harmful to the community.

As to the questions regarding individual rights, individual rights exist and are enforceable. This allows the individual to claim infringement upon these rights and he may enforce and enjoy his rights as he deems fit. However, when exercising these rights negatively influences the community, his rights may be limited for the good of the community. Such a limitation is also echoed in section 36 of the Constitution. ${ }^{19}$

Should a person who has the resources not to suffer, especially during harsh times, suffer if the community suffers? The answer seems to be that ubuntu does not expect the individual to suffer with the community but does expect of the individual to use the resources he has available to lessen the suffering of the community. In other words: that which is expected when applying ubuntu is not that we suffer together but that we alleviate pain and suffering through our actions. In that scenario, ubuntu would expect the individual to curb his desires to the advantage of the community. It is therefore clear that contrary to how it appeared at the onset of this study, ubuntu does not lead to nor does it intend the disappearance of the individual. Ubuntu thus envisions an individual capable of humanness and caring, an individual who meets the requirements as set by the community and who strives to fulfil those requirements.

The above mentioned questions, statements and definitions lead to the question of how ubuntu has been entrenched in the interim and the final Constitution by the legislature and the courts and how ubuntu has influenced jurisprudence and legal discourse in South Africa. I will start the discussion with reference to the interim Constitution, and then move on to the 'final' Constitution and certain case law.

\section{A bit of history}

South Africa was a country in turmoil and conflict because black citizens were oppressed by a white government and Western-type law. Apartheid was in full swing and the country experienced unrest. Negotiations between the ruling white party, the apartheid

19 Sec 36(1) of the Constitution states that:

'a right in the Bill of rights may be limited by a law of general application to the extent that the limitation is reasonable and justifiable in an open and democratic society based on human dignity, equality and freedom taking into account all relevant factors including: (a) The nature of the right; (b) The importance of the purpose of the limitation; (c) The nature and extent of the limitation; (d) The relation between the limitation and its purpose; (e) Less restrictive means to achieve the purpose.' 
government and representatives of the black community started taking place yet this did not to relieve the tension in the country. ${ }^{20}$ After lengthy negotiations and conflict, an agreement was finally reached. This agreement brought the interim Constitution into being and formed the basis of a 'new' South Africa based on the values of equality, human dignity, freedom and ubuntu. ${ }^{21}$

\section{Ubuntu and the interim Constitution}

In the interim Constitution of South Africa, ${ }^{22}$ ubuntu was, for the first time, incorporated into South African law when it was expressly mentioned in the epilogue. This created the hope that the legislature had finally moved away from purely imposing Western laws and ideals on an African society. ${ }^{23}$ This change would consequently apply African values to an African society thus generating and allowing 'African solutions to African problems'. 24

The express reference to ubuntu in the interim Constitution created hope of an equal and just society which does not discriminate between people on the ground of their culture, race, gender or religious beliefs. The entrenchment of ubuntu, an African value, into the interim Constitution made it seem as if South Africa was finally a place for all South Africans.

The inclusion of ubuntu in the interim Constitution was significant as it was the first reference to be made to ubuntu in South Africa's legal history, and the first time that the legislators paid due regard to that which is inherently African. Some of the first cases which were decided by the Constitutional Court were decided under the interim Constitution incorporating the concept of ubuntu.

However, although ubuntu was included in the interim Constitution ${ }^{25}$ and used as a tool to decide constitutional cases, ${ }^{26}$ it

20 M Sanders Complicities: The intellectual and apartheid (2002) 1-3, P Waldmeir Anatomy of a miracle: The end of Apartheid and the birth of the new South Africa (2001) 5 - 39, 59 - 237.

21 In Azanian Peoples Organisation (AZAPO) v President of the Republic South Africa 19968 BCLR 1015 (CC), the Constitutional Court recognised the constitutional status of the epilogue containing the concept of ubuntu.

22 See specifically the epilogue of the interim Constitution, Act 200 of 1993.

23 Mokgoro (n 5 above) 364-366.

24 M Goldmann 'Sierra Leone: African solutions to African problems?' (2005) 9 Max Planck Yearbook of United Nations Law 457-515. The phrase 'African solutions to African problems', which dates from the time when African states received independence, became widespread in the aftermath of the 1994 genocide in Rwanda when many Africans shared the feeling that they were better off if they found ways to tackle their problems themselves instead of relying on the United Nations and the Western world.

$25 \mathrm{Sec} 31$ of the interim Constitution provided for the freedom of every person to participate in the culture of their choice.

26 Makwanyane (n 1 above); PE Municipality (n 1 above). 
was not defined or accepted as a Constitutional value. ${ }^{27}$ The courts applied ubuntu as a constitutional value equal to other constitutional values ${ }^{28}$ but the legislature neglected to define ubuntu as a constitutional value. Each court must therefore apply the concept as it sees fit. ${ }^{29}$

\section{Ubuntu and the 1996 Constitution}

The failure to carry the concept of ubuntu over to the 1996 Constitution left a lot of South Africans legal scholars with the question why ubuntu was not carried over? ${ }^{30}$ Further, it also left open the question whether or not the legislature still deemed ubuntu as an important part of South African law and as a constitutional concept. It begs the question: why has ubuntu not been given a concrete definition in South African law and what meaning have the South African courts given to ubuntu? How, if at all, did the courts apply ubuntu to the law in South Africa? Further, what effect did the courts' interpretation and treatment of ubuntu have on the concept of ubuntu in South African law? To answer these questions, a critical approach has to be applied when examining the legislation and the judgements of the Constitutional Court.

During this assessment certain uncomfortable questions will have to be asked - questions such as whether the exclusion of ubuntu from the 1996 Constitution was caused by oversight or was it something more sinister such as deliberately leaving ubuntu out of the Constitution to 'de-Africanise' the 1996 Constitution? To answer these questions I refer to prominent case law, legislation and prominent writers on the topic of ubuntu.

I start my search for answers to these questions by examining the text, spirit and purport of the 1996 Constitution. When examining the epilogue, together with sections $17,9,10,11,12,14$ and 39 of the Constitution, it is clear that the values of human dignity, equality, life, privacy and freedom are clearly entrenched and that the courts, when interpreting any legislation or State action, are bound to respect these values. These sections from the Constitution clearly resemble some of the values of ubuntu as they are discussed in the paragraph on the definition of ubuntu.

Therefore, it appears to me that the legislature did not deem it necessary to expressly mention and entrench ubuntu as it would have

The Constitution does not define ubuntu.

$\mathrm{K}$ van Marle \& D Cornell 'Exploring ubuntu: Tentative reflections' in D Cornell \& $N$ Muvangua (eds) Ubuntu in the law of South Africa (2011) 452-477. 
been redundant and repetitive, as the relevant sections of the Constitution already entrench and enforce the core values of ubuntu. These values are, however, expressed in different terminology.

With reference to the principle of communality which forms part of ubuntu, I examined section 36 of the Constitution. This section is commonly known as the limitation clause as it limits the rights and freedoms of the individual, to protect other individuals and the society from misuse and abuse of freedoms and rights.

This section was not specifically written and entrenched to serve the community, but it can be interpreted and applied in such a manner that it can sometimes serve the purpose of protecting the community from individual actions which are harmful to the community. It is herein that the resemblance of section 36 and the communal aspect of ubuntu is to be found. This section cannot be equated to the communal aspect of ubuntu, but it can serve as an explanation as to why constitutional writers or the legislature did not deem it necessary to specifically mention ubuntu in the final Constitution. Section 38 determines who has locus standi in certain actions while it also determines that an individual can act on behalf of a community and therefore this section serves as an example of how the community is protected under the Constitution. ${ }^{31}$ Furthermore, it also enforces and emphasises the communal value contained in ubuntu.

After the examination of these sections I am of the opinion that although there is not an explicit reference to ubuntu in the Constitution, the principles of ubuntu is entrenched in the Constitution. All that is needed to make ubuntu part of South African law is a little creative thinking and persistence on the part of the jurist when interpreting the Constitution. When I say this I do not mean that 'ubuntu should mean anything to any man'. 32

The interpretation of the Constitution provides for the use and interpretation of indigenous law during legal disputes. ${ }^{33}$ Therefore indigenous law, which includes the concept of ubuntu can be implemented in line with already existing law. It is during legal disputes that a jurist must research the concept of ubuntu, interpret and present ubuntu as a viable concept to the courts. Thereafter, the courts should pay due regard to the concept of ubuntu and the interpretations of ubuntu that were presented to court. approach a competent court, alleging that a right in the bill of rights has been infringed or threatened. These include (1) Anyone acting in own interest (38(a)) (2) Anyone acting as a member of, or in the interest of, a group or class of persons (38(c)) and (3) Anyone acting in public interest (38(d)).

33 Bekker (n 12 above) 491.

33 Sec 39 of the Constitution. 
Ubuntu should truly be considered and not just used and referenced as an afterthought. The best chance of survival ubuntu has is if the concept of ubuntu is judicially defined. Thus, in answer to the questions stated above, in my opinion the express reference to ubuntu was not carried over from the interim Constitution to the 1996 Constitution because the writers of the Constitution did not deem it necessary to expressly entrench ubuntu as a constitutional value as there are other values in the Constitution which resemble the values expressed by the concept of ubuntu. Call it negligent and inconsiderate at most but at least the removal does not, in my opinion, amount to anything sinister such as the 'de-Africanisation' suggested by some writers. ${ }^{34}$

\section{Case law: Facts and decisions}

In this section of the discussion I will start with references to case law and the references to the Constitution in the case law. In each case, I will first give a short overview of the facts, then the relevant provisions of the Constitution surrounding the case and lastly I will discuss the application of ubuntu. For ease of reading, the discussion is divided into two parts: first a discussion of cases decided under the interim Constitution and then cases decided under the 1996 Constitution.

\subsection{The interim Constitution}

One of the most important cases and certainly one of the most influential in South African law is $S v$ Makwanayane. ${ }^{35}$ I examine this case not for its importance in criminal law but because it is the first case in which the judges explicitly referred to ubuntu. This case, reported in 1995, was one of the first cases heard by the South African Constitutional Court.

The case was heard under the interim Constitution and thus under the Constitution which recognised ubuntu. In short, the facts of the case are as follows: Makwanyane and his accomplices were prosecuted and found guilty on multiple counts of murder, attempted murder and robbery with aggravating circumstances. The court a quo imposed the death penalty on Makwanyane and the other defendants. Makwanyane appealed against the decision of the court but the appeal was dismissed and the death penalty retained. The appeal process continued until the case reached the Constitutional Court.

E Moosa 'Tensions in legal and religious values in the 1996 South African Constitution' in M Mamdani (ed) Beyond rights talk and culture talk: Comparative essays on the politics of rights and culture (2000) 131. See also Van Marle \& Cornell (n 30 above) 464.

35 S v Makwanayane \& Others 19956 BCLR 665 (CC). 
The appeal was based on the grounds that the death penalty infringed the defendant's right to life and dignity as set out in sections 10 and 11 of the Constitution 36 and that the death penalty constituted punishment which is 'cruel and inhuman' and that under the new constitutional disposition no person may be subjected to 'cruel, inhuman or degrading' punishment. ${ }^{37}$ Thus the issue for consideration in the case was the constitutionality of the death penalty and whether or not it infringes the constitutional rights of the accused. ${ }^{38}$

Accordingly, the court considered the appeal and the death penalty was abolished by the majority of the court. Although Sachs J formed part of the majority abolishing the death penalty, he delivered his own separate judgment expressing certain concerns regarding ubuntu as a constitutional value. Sachs J discussed the question regarding the use of ubuntu in great detail, asking questions such as why ubuntu was not brought before the court for argument and how ubuntu should be interpreted. He goes on to give an explanation of how he believes ubuntu can be used in legal disputes. Further Justice Sachs showed a concern with the sources of South African law and indicated that African (indigenous) law should be used as a source of law yet he failed to give concrete meaning to the concept of ubuntu and how it should or could be developed in South African law. Ubuntu thus remains an unclear concept.

Apart from expressing a concern about African and indigenous law not being considered and developed under the interim Constitution, the judgment does not contribute to the entrenchment or development of ubuntu as part of South African law.

The manner in which the judgment reads and the manner in which ubuntu was discussed by Constitutional Court judges makes it seem as if the judgment had a political character. ${ }^{39}$ Confusion remains regarding the Constitutional Court interpretation of ubuntu as a necessary legal principle to be considered when deciding cases. A person examining ubuntu may, with reason, wonder what value ubuntu has for South African law if the Constitutional Court although considering ubuntu properly fails to give concrete meaning and application to ubuntu as a constitutional value.

In my opinion, the effect goes much further than anticipated. I stated earlier that I do not think and cannot imagine that the drafters of the Constitution deliberately left the concept of ubuntu out of the 1996 Constitution with the purpose of de-Africanising the Constitution has the right to life'.

37 Sec 12(1)(a)-(e) of the Constitution contains the right to freedom and security of the person.

38 Sec 10 of the Constitution: everyone has inherent dignity and the right to have

their dignity protected and respected.

39 Bekker (n 12 above) 491-492. 
nor do I think it was an oversight. After examining the Constitutional Court's decision under the interim Constitution and the little regard they had for the principle of ubuntu while it was entrenched in the epilogue of the interim Constitution, it is my opinion that it may be possible that the drafters removed the term ubuntu from the Constitution and entrenched the principles associated with ubuntu in other sections of the Constitution as they did not deem it necessary to entrench the concept of ubuntu into the Constitution.

\subsection{The 1996 Constitution}

One of the most important cases heard under the 1996 Constitution is that of Port Elizabeth Municipality $v$ Various Occupiers (PE Municipality) ${ }^{40}$ as it deals with the rights of people to housing and land occupation. The facts in short are that some squatters occupied a piece of privately owned land. The Port Elizabeth municipality applied for an eviction order against the squatters. The municipality argued that they were allowed to evict the squatters as the squatters were unlawfully occupying the land. Furthermore, the municipality argued that they were not obliged to provide the squatters with alternative housing. The squatters, on the other hand, argued that the municipality arbitrarily evicted them from the land and did not comply with the relevant legislation required when a person, institution or company intends to evict squatters from the land. The squatters furthermore argued that due to the municipality's noncompliance with the relevant legislation, ${ }^{41}$ the municipality acted in a way that was inconsistent with the Constitution ${ }^{42}$ and unfair, so that its actions were constitutionally reviewable. The squatters also argued that there was an obligation on the municipality to provide them with alternative housing.

The court $a$ quo held that there was no duty on the municipality to provide the squatters with alternative housing before evicting them and therefore the court granted the eviction order. Thereafter, the squatters approached the Supreme Court of Appeal which set aside the eviction order and held that the municipality was obliged to provide the squatters with alternative housing.

Thereafter the municipality applied to the Constitutional Court for leave to appeal, the restoration of the eviction order and an order setting out that the municipality was not obligated to provide

200412 BCLR 1268 (CC).

41 The Prevention of Illegal Eviction from and Unlawful Occupation of Land Act 19 of 1998 (PIE Act).

42 Sec 26(3) of the Constitution states that 'no one may be evicted from their home, or have their home demolished, without an order of Court made after considering all relevant circumstances'. 
alternative housing when evicting unlawful occupiers. ${ }^{43}$ The Constitutional Court denied the municipality's appeal and held that the municipality had to comply with all relevant legislation. Therefore, there was a duty on the municipality to participate in mediation procedures with the occupiers it aimed to evict from the land in order to provide alternative housing to the occupiers.

The Constitutional Court accordingly found that the municipality acted in an arbitrary manner and that the municipality's actions infringed the right to housing and other Constitutional rights of the squatters. It is interesting to see that in the Port Elizabeth Municipality case, Sachs J invoked ubuntu. Sachs J delivered the judgment in this case and he once again referred to ubuntu when he interpreted the Constitution including the right to housing ${ }^{44}$ and the right to private property. ${ }^{45}$ This reference to ubuntu had the effect that the squatters' right to housing as well as the right to own private property had to be taken into account when determining the legality of an eviction notice, as well as the responsibility of the state to provide housing to the squatters.

In South African law, each case has to be decided on its own merit, taking all relevant circumstances into account, as it is the only way to achieve results which are fair, equal and reasonable in a new and democratic South Africa. In this case the court held that, in accordance with ubuntu, the state has a responsibility toward the squatters and that the state has a duty to protect the poor and vulnerable groups of society. Further, Sachs J held that PIE Act must be interpreted in accordance with the values of the Constitution and the communitarian attitude encapsulated in the concept of ubuntu. From this judgment, it is clear that both sections 25 and 26 of the Constitution as well as the PIE Act are informed by ubuntu. Further, the judgment makes it clear that when considering socio-economic rights, the concerns of the community as a whole should be safeguarded and taken into account. This is nothing other than expressing a value of ubuntu in plain English. Did the court give an express meaning or at least a more concrete meaning and interpretation of ubuntu?

To answer this question I have to compare the PE Municipality case with the Makwanyane case. When comparing these two cases concerning the application of ubuntu in South Africa, it is clear that

PE Municipality (n 1 above).

Sec 26 provides that everyone has the right to have access to adequate housing and further in sec 26(2) that 'the state must take reasonable legislative and other measures, within its available resources, to achieve progressive realisation of this right'. Sec 26(3) adds that 'no one may be evicted from their home, or have their home demolished, without an order from the court made after considering all relevant circumstances.'

45 Sec 25(1) stipulates that 'no law may permit arbitrary deprivation of property'. 
some progression has been made in the use of ubuntu during legal proceedings and when the protection of fundamental rights are at issue. The progression lies in the fact that while ubuntu was entrenched in the interim Constitution and reference was made to ubuntu in the Makwanyane decision regarding the death penalty, ubuntu was not entrenched under the 1996 Constitution, and yet still the majority judgment in PE Municipality case decided by Sachs J unambiguously referred to the concept of ubuntu.

\section{Conclusion}

I have now discussed the most relevant material and will now attempt to answer the questions as stated throughout the article. Is there another more universal term which can replace ubuntu? The short answer is no, because ubuntu is a traditional and uniquely African concept. Other concepts might come close and may resemble ubuntu but they are not the same.

I examined both the concept of ubuntu and humanitarianism and thereafter compared the two concepts with each other. Through the comparison it was clear that the two concepts, while reflecting and promoting some of the same principles, differ substantially in other respects. It is clear that humanitarianism, a Western concept, still holds the individual central to the philosophy of the concept while ubuntu has at its centre the community.

When dealing with humanitarianism it is clear that the community's welfare is important and the concept does promote communal values, but the concept promotes these values because the welfare of the community enhances the welfare of the individual. Humanitarianism, just as ubuntu, has as its core philosophy that people should be treated humanely and with dignity and respect but it differs from ubuntu in the sense that humanitarianism places an emphasis on the individual while ubuntu requires that we move away from the individual and place society as a whole at the centre of our law and way of life.

The question whether or not ubuntu removes the individual's identity has already been dealt with but I will briefly repeat that the individual is not stripped of his individual identity. The individual is challenged to form and create his identity in a way that it is in accordance with the values of the community and to develop an identity, lifestyle and life orientation which does not damage the community but which promotes and advances the community. Ubuntu is not based on the belief in suffering together. In other words, it does not mean giving up your resources for the community so that, when the community suffers, every individual, even the individual who does not need to, suffers. Ubuntu, after close examination and extensive research, seems to have as its purpose that an individual who has the 
resources to take care of himself and the community should and may do so. Ubuntu does not expect of the individual to give up all his rights but it does expect the individual to act in a manner which is to the advantage of the community. Ubuntu also expects an individual to curb his desires if his desires affect the community negatively. It is clear that ubuntu is a philosophy of life and law which holds the promotion of the group central but it does not expect the impossible or the unreasonable from the individual. Ubuntu does not expect the individual to suffer because the group is suffering but ubuntu does expect the individual to use his resources in such a way that the resource promotes the group or community and not the individual.

However, care must be taken so as not to turn the ideal of ubuntu into a reality that has a part of society carry the burdens of the rest of society. Ubuntu must be applied in a manner which promotes unity in the community without creating dependence of one group in society on another group in society. Ubuntu should remain a concept where the focus is on respect, dignity and the welfare of the community because communities, irrespective of race, gender or ethical orientation, are dependent on each other. There can be no talk of ubuntu or a true post-apartheid South Africa before the different communities in our society start taking care of or at least start considering each other. For ubuntu to be a viable concept, it must not just be developed in law, the concept must be made part of everyday language and everyday living. Only after we have made the values of ubuntu part of our everyday lives and we again begin taking care of each other and our communities then can we truly start to entrench ubuntu in our law.

As to the question of whether or not ubuntu should be entrenched into South African law I am of the opinion that the Constitution provides for the protection of the core values of ubuntu. Although it would have been satisfying to see an explicit reference to ubuntu in the 1996 Constitution the fact that there is no such explicit reference to ubuntu in the Constitution does not prevent ubuntu from being part of South African law. The Constitution allows the writing of legislation promoting and protecting the Constitutional values, therefore ubuntu can become part of South African law through such legislation. The focus must, in my opinion, be on the development of ubuntu as a national concept before entrenching the concept in legislation.

In this article, I only examined two cases; there are other cases which can also be examined. I chose the two cases because they illustrate the point I was trying to make most effectively. The examination of Makwanyane clearly illustrates the regard that the Constitutional Court has for the concept of ubuntu and indigenous law and the case establishes a starting point for the development of ubuntu. 
Therefore, it does not come as a surprise that the reference to ubuntu was not carried over to the 1996 Constitution. I considered the possibility that the reference to ubuntu was left out as an attempt to de-Africanise the 1996 Constitution and in that way limit the legal sources to those already accepted as legal sources in South African law. However after an examination of both Constitutions and the two cases heard under the interim Constitution and the 1996 Constitution respectively, it is clear that this was not the case and that the Constitutional Court built on the previous decisions of the court and is starting to refer to ubuntu more readily.

In the PE Municipality case, the Constitutional Court accepted the concept of ubuntu and started to develop the concept. The court started the application of ubuntu on the basis which was laid by $S v$ Makwanyane and gave as much, if not more, consideration to the influence of ubuntu on the South African law. This development took place even though ubuntu was not entrenched in the 1996 Constitution. In the PE Municipality case, the Court, even though the Constitution did not entrench ubuntu, was prepared to develop ubuntu as the court had a previous judgment to support the development and other sections of the Constitution resemble the principles of ubuntu. Whichever reason it may be, the move away from only applying those sources already accepted as sources of law to applying sources that are unique to Africa is a long-awaited shift.

When examining the writings on the topic of ubuntu it is clear that there is a lot of positive and negative critique on the subject, especially on the Constitutional Court judgments. Critique included the idea that Sachs J's judgment in Makwanyane is incomplete and that there was no concrete definition or application of ubuntu in the judgment, ${ }^{46}$ and this critique is understandable. When I started my research on the topic I held the exact same critique. I am still of the opinion that it is necessary to define, or rather redefine, the concept of ubuntu. I hold this opinion because as ubuntu stands now it has a strong cultural meaning which fits an African culture. It is also a concept which Western cultures do not understand and cannot comprehend because, even though they have concepts similar to that of ubuntu, it is not exactly the same as that of ubuntu since their cultures are based on individualism and not communitarianism.

Therefore I am of the opinion that before ubuntu can be reintegrated into a South African society it must be redefined. I realise that defining and redefining ubuntu is not as easy as it may appear. Defining ubuntu in plain English alone is a nearly impossible feat as it cannot be separated from the cultural connection it has. This is experienced as a problem by the majority of the writers on the subject but I came to realise that keeping the definition of ubuntu 
connected with its cultural contexts might be an ideal way to deal with ubuntu. ${ }^{47}$ I suggest that instead of translating ubuntu into English and trying to explain the cultural connection but failing to do so, legal scholars should consider moving away from translation and definitions of words and concepts and should aim to transform society and culture from a society and culture which is separated and distant from each other to a society that takes care of each other and shares a mutual respect and responsibility for each other. In other words, the community will have to be socially and culturally redefined.

How we, as society, achieve social and cultural redefinition and thus how we then redefine ubuntu, depends on how our courts and legislature interpret the Constitution in relation to ubuntu and on how we, as citizens and legal scholars, interpret and allow others to interpret the Constitution and ubuntu. I am of the opinion that after society has been transformed into a community based on respect and equality then only will we be able to obtain a universal and social definition of ubuntu.

To conclude, I am of the opinion that to define or redefine ubuntu, it is important to redefine our society and our identity as South Africa. I caution against Westernising an African concept and Africanising a Western concept and advocate for a merger of the concepts of ubuntu and humanitarianism to create a concept unique to South Africa which finds a midway between humanitarianism and ubuntu. The approach must recognise that in some situations the community must get preference and in other situations the individual should get preference. Thus, I suggest that, when ubuntu and humanitarianism is merged, ubuntu as currently defined to mean 'I am a human being through other human beings' will be extended. ${ }^{48}$ । therefore suggest that, by taking social context into account, the new concept may result in ubuntu being understood as 'I am a person through other people yet in some reasonable circumstances the needs and right of the individual will receive preference above that of the community'.

$47 \quad \mathrm{~N}$ Bohler-Müller 'Some thoughts on the ubuntu Jurisprudence of the Constitutional Court' in Cornell \& Muvangu (n 31 above) 486- 488, Bekker (n 12 above) 491-493. 48 Mokgoro (n 5 above) 363. 